\title{
Burguesía nacional y Estado: la acción política de la Unión Industrial Argentina durante la Revolución Argentina (1966-1969) *
}

\author{
Verónica Baudino
}

Centro de Estudios e Investigación en Ciencias Sociales, Buenos Aires, Argentina, Becaria CONICET. Email: veronicabaudino@yahoo.com.ar

Resumen: El presente artículo tiene como objetivo reconstruir las relaciones de la fracción de la burguesía nacional representada por la Unión Industrial Argentina y el Estado Nacional entre 1966 y 1969. Es decir, comprender el plan de acción llevado a cabo ante el gobierno llamado "Revolución Argentina”, liderado por Juan Carlos Onganía. Para ello, examinaremos las líneas rectoras de la institución en materia salarial, arancelaria, fiscal, macroeconómica y política. Analizaremos entonces la intervención de la entidad durante el gobierno de Onganía, como parte integrante del mismo. Observaremos qué propuestas elevaron en cada momento y qué discusiones sostuvieron con las autoridades vigentes.

Palabras clave: Burguesía, estado, Unión Industrial Argentina, estrategia

\section{National bourgeoisie and State: the political action of the Argentinian Industrial Union during the Argentinian Revolution (1966-1969)}

\begin{abstract}
The aim of this paper is to reconstruct the relationship between the national bourgeoisie, represented by the Union Industrial Argentina, and the State, between 1966 and 1969. This is, to understand the plan of action undertaken by the governemental period calkled “Argentinian Revolution” lead by Juan Carlos Onganía. To this end, we examine the guidelines governing the institution in terms of its wages, tariff, fiscal policy, macroeconomics and politics. We analyze the involvement of the organization, during the government of Juan Carlos Ongania, as an integral part of it. We note which proposals they raised each time and what discussions they held with national authorities.
\end{abstract}

Key words: Bourgeoisie, state, Unión Industrial Argentina, strategy

\section{As relações entre a burguesia eo Estado Nacional durante a Revolução argentina (1966-1969)}

Resumo: O objetivo deste trabalho é reconstruir a relação entre a burguesia nacional, representada pela IndustrialArgentina União e do Estado entre 1966 e 1969. Para este fim, vamos examinar as diretrizes que regem a instituição em termos de salários, tarifas, fiscal, macroeconômicas e da política. Analisamos o 
envolvimento da organização, durante o governo de Juan Carlos Onganía, como parte integrante da mesma. Notamos que as propostas levantadas em qualquer momento e que as discussões realizadas com as autoridades nacionais. Palavras-chave: Burguesia, estado, Unión Industrial Argentina, estratégia

\section{El gobierno de Onganía}

La dictadura instaurada en 1966 ha sido caracteriza por el cientista social Guillermo O’Donnell como un "Estado burocrático Autoritario" (O’Donnell 1984 y 2009) cuya finalidad habría sido constituirse como el representante de los intereses de una fracción particular de la clase dominante: la gran burguesía. El objetivo del golpe, a juicio del autor, era normalizar la dinámica de acumulación argentina, basada en una lógica cortoplacista y de saqueo, propia de los países dependientes. En este sentido, el gobierno militar pretendió generar contextos de acumulación que alejaran a la gran burguesía de su comportamiento especulativo, estrategia que habría fracasado.

A juicio del autor, un "Estado burocrático autoritario" (BA) se caracteriza porque: (a) "Es, primaria y fundamentalmente, el aspecto de la sociedad global que garante y organiza la dominación ejercida a través de una estructura de clases subordinada a las fracciones superiores de una burguesía altamente oligopólica y transnacionalizada. Dicho de otra manera, su principal base social es la gran burguesía.” (O’Donnell 1982: 19-64). (b) Institucionalmente cobran peso la coacción y los programas de normalización de la economía. (c) Tiende a la exclusión política. (d) Suprime la ciudadanía y la democracia política. (e) Excluye económicamente al sector popular. (f) Cierre de los canales de acceso al gobierno, excepto para las FFAA y las grandes empresas privadas y públicas.

Se diferencia de otras experiencias autoritarias latinoamericanas porque no se asienta primeramente en oligarquías y capitales transnacionalizados insertos en actividades primarias exportadoras, dominantes sobre una población de escaso contenido obrero y poco movilizada. Tampoco se trata de una experiencia "populista anti-oligárquica” basada en el crecimiento al calor de medidas proteccionistas, que forjan una alianza con sectores medios y bajos recientemente activados. Por último, según O’Donnell, el BA contrasta con el fascismo dado que éste se asentó en burguesías más "propiamente nacionales" que las del BA, a la vez que el rol del partido es reemplazado por otro actor: las Fuerzas Armadas.

Las cualidades centrales del régimen propuesto por O’Donnell, que se sintetizan como Estado burocrático-autoritario, no dan cuenta, a nuestro entender, de una situación históricamente excepcional, como este autor pretende demostrar. En primer lugar, dado que por su carácter y sus funciones como garante de la dominación social, todo Estado es autoritario. A su vez, 
en tanto su función es la de legislar y encauzar la forma que toma la dinámica social de modo que permita la reproducción del sistema, se sirve de todo un "aparato” administrativo, denominado burocracia. En todo caso, en períodos de crisis se instauran regímenes de tipo dictatoriales, en los que no cambia la esencia del Estado sino la forma política en la que se implementa la represión o el "autoritarismo" (de modo más abierto y violento que en los períodos democráticos) (Sartelli 1996). La exclusión política, la supresión de la ciudadanía y la democracia política, la relegación económica del sector popular y el cierre de canales de acceso al gobierno no constituyen características de un tipo de Estado particular, sino el contenido de un régimen político (la dictadura) específico en determinado momento histórico (Marx 1998:60-61). Es más, muchos de los mencionados rasgos están presentes en todos los regímenes políticos burgueses en mayor o menor medida.

Nuestro siguiente punto de desacuerdo refiere a la base social del Estado burocrático autoritario de O’Donnell: la gran burguesía. A entender del autor, el objetivo del nuevo gobierno habría consistido en "normalizar" la economía, borrando los rasgos propios de un país dependiente: saqueo y especulación. En primer lugar, dicha caracterización de las peculiaridades del capitalismo argentino y de la burguesía nacional presupone un comportamiento ausente de inversiones a largo plazo que, en el mundo real, imposibilita cualquier acumulación. El cortoplacismo y la especulación sobre los que tanto se insiste en la bibliografía carecen de pruebas que sustenten dicha teoría. ${ }^{1}$ En segundo lugar, si el saqueo y la especulación constituyen la base de acumulación de la gran burguesía, es contradictorio que ésta haya sido el sustento social del BA. ¿Cuál es la razón por la cual la burguesía más concentrada apoyaría un régimen tendiente a socavar su fuente de ganancia? Antes bien, el propósito de Onganía parece haber sido resolver la crisis de acumulación generalizada del capitalismo argentino. Así la adhesión del gran capital parece condecirse con la perspectiva de resolver sus dificultades para obtener ganancias.

Al observar la dinámica política que adopta el gobierno de Onganía, el punto de apoyo difiere del que marca el autor reseñado. El lugar en la estructura de poder y las políticas económicas que se otorgó a las diferentes fracciones de la burguesía indica que el régimen en cuestión oscilaba entre sectores en pugna. Se dividieron los ministerios y cargos políticos de modo tal que cada fracción de la burguesía, y cada facción política del Ejército, controlasen una porción de la administración. Los paternalistas, nacionalistas y liberales, tendencias internas del ejército, recibieron respectivamente su tajada. Tanto las corporaciones industriales de la gran burguesía (Krieger Vasena, ministro de Economía entre 1967 y 1969, se alineaba con la UIA y el Consejo Empresario Argentino), como las de la burguesía mediana y pequeña (Salimei, ministro de Economía entre 1966 y 1967, estaba relacionado con la CGE), tuvieron en diferentes momentos representación en el gobierno. Hasta dos de los tres sectores en que se dividió el movimiento obrero dieron su apoyo al gobierno de facto, e incluso luego de constatar el carácter antiobrero de las políticas implementadas, se mantuvo 
el coqueteo de un sector del gobierno con los sindicatos. De esta forma, Onganía pretendía equilibrar el poder de cada fracción.

El gobierno de Onganía no parece haber expresado los intereses de una de las fracciones de la burguesía, sino que intentaba sintetizar las pretensiones de cada una de ellas. Ante el quiebre en la cúpula de la burguesía vigente desde 1955, Onganía constituyó una experiencia de tipo bonapartista que tuvo por fin lograr la paz intraburguesa y restituir finalmente su hegemonía. ${ }^{2}$

En suma, la dictadura acaudillada por Onganía pretendía restaurar las condiciones de reproducción de un capitalismo en crisis y restablecer cierto equilibrio entre las diferentes fracciones de la burguesía en pugna mediante un régimen bonapartista. La búsqueda de resolver las contradicciones inter-burguesas que impedían el cierre de la crisis hegemónica y el alza de la lucha de la clase obrera no fue posible, como demuestra la profundización de las contradicciones, luego de la rebelión popular de 1969 denominada Cordobaza (Balvé 2003). La Unión Industrial Argentina, en la situación planteada, llevó adelante una estrategia para lograr políticas afines a sus intereses intentando que el gobierno de Onganía se convierta en el representante de algunos de los capitales más concentrados de la Argentina. Indagaremos las ideas defendidas por la entidad y su incidencia en el gobierno en los acápites que siguen.

\section{La intervención de la UIA frente al gobierno de Onganía.}

\section{El respaldo al golpe militar}

El plan de la dictadura militar instaurada el 28 de mayo de 1966, comandada por el general Juan Carlos Onganía, se desarrollaría en tres etapas, denominadas tiempo económico, social y político, que se debían suceder unas a otras. La primera etapa apuntaba a solucionar las cuestiones económicas, basándose en el crecimiento de los sectores más eficientes. El segundo sería el "tiempo social”, cuyo eje sería la redistribución. El último de los tiempos, el político, consistiría en la apertura a la participación de la sociedad (Bra 1985; Anzorena 1998; Perina 1983; Casanova 1998) .

Entre las principales medidas políticas contamos la disolución de legislaturas nacionales y provinciales, y la prohibición de los partidos políticos. Se implementaron políticas de control de la actividad sindical mediante la SIDE (Secretaría de Inteligencia de Estado), delineadas en el CONASE (Consejo Nacional de Seguridad). Se intervinieron los medios de comunicación y las universidades nacionales, proceso que terminó en la represión de la resistencia estudiantil en la "Noche de los bastones largos". Este último conflicto comenzó cuando a fines de julio de 1966 el Poder Ejecutivo Nacional, por ley 16.912, dictaminó que el gobierno de las Universidades estaría a cargo de los rectores, decanos o presidentes, cancelando el sistema de gobierno universitario. Las atribuciones de los consejos 
superiores o directivos se traspasarían al Ministerio de Educación. En respuesta a las medidas tomadas, las universidades iniciaron medidas de lucha que culminaron con una fuerte represión por parte del gobierno (Bra 1985: 9 y 10).

La UIA estuvo compenetrada en el golpe desde sus inicios. Inclusive, meses antes del derrocamiento de presidente radical Arturo Illia, en la revista de la entidad se publicó un artículo en el que se ponderaba la importancia de contar con un Ejército que actúe en determinadas coyunturas en las que el desarrollo integral de la nación (material y espiritual) se vea comprometido. Allí se ponía el acento en la necesidad de que el Estado cumpla plenamente con sus funciones de garante de la seguridad tanto externa como interna (Revista de la UIA, 1966: 48). Dejaba sentado así que el Ejército debía intervenir en caso de ponerse en cuestión la normal reproducción de espacio nacional de acumulación, justificando su alineamiento junto a las fuerzas golpistas que derrocaron a Illia y la defensa de las Fuerzas Armadas como un personal idóneo para la resolución de crisis políticas.

Una vez consumado el golpe, la entidad concurrió al acto de asunción de la autoridad entrante, así como al del nombramiento del ministro de Economía Jorge Néstor Salimei. Se hicieron presentes allí también representantes de la Confederación General Económica (CGE), Sociedad Rural Argentina (SRA) y Federación Agraria Argentina (FAA), dando muestras del amplio apoyo que recibió el nuevo gobierno (Cronista Comercial: 1966). Un mes después de la instauración del régimen militar, la UIA lanzó un comunicado de prensa en el que llamaba a todos los argentinos a contribuir "con su acción y con su palabra a la tarea urgente de la reconstrucción nacional” (Cronista Comercial: 1966). Es decir, llamando a respaldar las tareas asumidas por el gobierno entrante. A su entender, la crisis que se vivía “no es sólo ni principalmente económica” (Cronista Comercial: 1966), y dejaba sentadas las bases de su programa económico sobre la que volveremos más adelante.

En función de establecer estrechas relaciones e intentar imponer su proyecto, la institución, a lo largo de los primeros meses del nuevo gobierno, llevó adelante reuniones con el ministro de Trabajo, Juan Pedro Tamborenea (Cronista Comercial: 1966), con el ministro de Bienestar Social, Roberto Petracca (perteneciente a la UIA), el de Vivienda, Ernesto García Olano, así como con el presidente Onganía. En oportunidad de una reunión con este último, el principal dirigente de la UIA, Juan Martín Oneto Gaona, declaró: "Ha sido una entrevista fantástica [...] Siempre estoy satisfecho pero hoy me encuentro más que satisfecho.” (Cronista Comercial: 1966).

El sentido de estas palabras se reiteró en los discursos de los dirigentes de la UIA en la celebración del Día de la Industria. Lo hizo ante un auditorio de notables figuras políticas, entre los que se encontraban representantes de ACIEL (Acción Coordinadora de Instituciones Empresarias 
Libres), SRA (Sociedad Rural Argentina), CAC (Cámara Argentina de Comercio), el secretario de Industria, Mario Galimberti, el ministro de Economía Salimei, el presidente de la Corte Suprema, el canciller Nicanor Costa Méndez y el comandante de operaciones navales Benigno Varela, entre otros. Oneto Gaona, en esta oportunidad exaltó las aspiraciones del nuevo gobierno nacional de transformar profundamente el sistema político ( $L a$ Nación: 1966).

El soporte de la UIA a las líneas trazadas por la Revolución Argentina se expresó posteriormente en los festejos del Día de la Industria en 1967, cuando Oneto Gaona expuso nuevamente su acuerdo con el proceso iniciado por la dictadura de Onganía. Allí comprometió el "esfuerzo” de los industriales en la empresa del gobierno, tendiente a superar el estancamiento en que se había sumergido a la nación (La Nación: 1967).

Como vemos, la UIA apoyó la intervención y la reconfiguración del mapa político que intentaba llevar adelante el gobierno militar. Constituyó una de las fuerzas que se disputaba la dirección que debía tomar el gobierno. En ese sentido actuó de manera diferenciada ante las políticas planteadas por los dos ministros de economía de la Revolución Argentina; Jorge Salimei primero, y Adalbert Krieger Vasea, después.

\section{Salimei: la oposición}

El primer Ministro de Economía designado por Onganía para liderar el proyecto fue Jorge Salimei, propietario de la empresa alimenticia Sasetru, director del Banco de Boulogne (Rouquie 1994) y de empresas de transportes, obras públicas y finanzas. Participaba de los Cursillos de Cristiandad y sus ocho subsecretarios también provenía de la Iglesia: formaban parte de la Asociación Católica de Dirigentes de Empresa. ${ }^{3}$ Era miembro de la Federación Económica de la Provincia de Buenos Aires, perteneciente a la CGE (Niosi 1974: 171). Todo su gabinete era de extracción burguesa. Sus estrechos vínculos con los generales retirados Señorans y Conesa habrían determinado su nombramiento al frente del ministerio.

La gestión de Salimei se desarrolló durante el año 1966, caracterizada por el estancamiento del producto bruto interno, la caída de la inversión bruta fija (en un 7,1\%), un leve ascenso de las inversiones extranjeras y déficit de balanza de pagos. Su plan estuvo signado por una política monetaria gradualista para el control de la inflación y cierto intervencionismo estatal, expresado en la persistencia del control de cambios. Su plan más recordado fue el llamado “Operativo Tucumán” consistente en una reestructuración de la rama azucarera asentada en la centralización de la producción mediante el cierre de ingenios y la modernización de la producción (Rapoport 2000).

Las intervenciones de la UIA de cara a las políticas implementadas por Salimei nunca fueron favorables. Ni bien asumidas las autoridades militares y Salimei en la cartera de Economía, la corporación empresarial 
expuso un programa económico caracterizado por una serie de presupuestos y medidas. Al Estado, la entidad le reservaba un rol como estimulante del desarrollo económico, inclusive mediante la inversión pública en nichos estratégicos no desarrollados por el capital privado. Las críticas de la UIA no se dirigieron a la gestión de Salimei en particular dado que el mandato recién se iniciaba. Marcaban, no obstante, la línea que se pretendía que adopten las nuevas autoridades nacionales y las del ministerio de Economía en particular. Expresaban la existencia de un Estado deficitario, ineficiente, que requería el saneamiento de su estructura (Cronista Comercial: 1966).

La política monetaria también fue terreno de definiciones. La inflación, a juicio de la entidad, había sido impulsada por gastos fiscales excesivos, salarios no ajustados a la productividad de la industria nacional y alto nivel de consumo. Su solución, en efecto, debía implicar el aumento de la tasa de explotación de los trabajadores, reiterada en muchas oportunidades durante el período (Cronista Comercial: 1966).

Las medidas de estabilización de la inflación debían conjugarse con la adecuación del valor de la moneda nacional con la realidad. Es decir, se solicitaba la devaluación del peso, juzgada como beneficiosa para incentivar el comercio exportador y disminuir los costos salariales. Asimismo, la intención de expandir sus mercados hacia el exterior presuponía para la entidad la necesidad de que el Estado tome la tarea de gestionar las relaciones con otros países y facilitar la reducción de costos para incrementar la productividad de sus industrias y lograr colocar la producción industrial en los mercados externos.

El último punto central en la primera formulación del programa de la UIA lo constituyó el sistema previsional. En 1954, mediante la sanción de la ley 14.370, el sistema pasó de ser por capitalización individual a reparto, en el que los trabajadores ocupados sostendrían de manera solidaria a aquellos trabajadores jubilados. En 1958, el gobierno de Frondizi sancionó la Ley 14.499 en la que se instauró que los haberes jubilatorios serían equivalentes al 82\% móvil del salario mensual asignado al cargo del afiliado (Basualdo 2009), estandarizando el nivel de los haberes. Este sistema fue fuertemente criticado por la UIA desde la asunción del gobierno de Onganía por ser “tan caro como ineficaz” (Cronista Comercial: 1966).

Asimismo, en otras exposiciones, la entidad clarificó su política con respecto a la clase obrera. Debían anularse aquellas "pseudo-conquistas" sociales que atentasen contra el desarrollo industrial general. Desde la Revista de la UIA, Carlos Coll Benegas ${ }^{4}$ describía la posición de la entidad ante los salarios. Su hipótesis consistía en que la inflación en Argentina era producto del "tremendo egoísmo de sus clases sociales". Era expresión de la lucha entre los distintos sectores sociales por retener para sí una amplia porción de la riqueza nacional y se desencadenó a partir de la política salarial del peronismo (Revista de la UIA, 1966: 40). La propuesta de la UIA ante tal caracterización fue la aplicación de congelamientos salariales. 
A fines de 1966 la entidad participó, con esta línea, en el Consejo Nacional de Salario Vital, Mínimo y Móvil. Intervino allí planteando que las distintas resoluciones adoptadas por el Consejo habían desvirtuado el sentido y el concepto de las remuneraciones, particularmente con respecto a las adoptadas para aprendices y menores, retribuciones por antigüedad y escalafones. También señaló que se distorsionaba el régimen de los jornales en razón de la permanente vinculación de las asignaciones familiares con el salario mínimo, que desalentaba el esfuerzo personal. Por último, objetó la vinculación de los sueldos con las indemnizaciones por despido, ya que de esa forma éstas se elevaban constantemente (Memoria y Balance UIA, 1967).

Por otra parte, en función de la necesidad de lograr estabilidad en términos inflacionarios, la UIA presentó posiciones ambiguas con respecto al "Acuerdo de precios" propuesto por el ministro de Economía. El mismo fue lanzado por las autoridades militares, en 1966, con el fin de lograr la cooperación del empresariado para controlar las alzas de precios y así evitar un mecanismo de coerción por parte del Estado sobre el empresariado. La UIA se resistió al Acuerdo durante la gestión de Salimei. Con motivo de una reunión de empresarios de diversas organizaciones (UIA, Confederación General Económica, Cámara Argentina de Comercio y la Acción Coordinadora de Instituciones Empresarias Libres) con el subsecretario de comercio, Manuel Crespo, para tratar la propuesta del gobierno. Allí, el ministro alertó sobre una política de estímulo hacia quienes "respondieran positivamente al llamado oficial, y de compulsión y desaliento a quienes no aportaran al sacrificio comunitario" (Cronista Comercial, 1966). El "castigo" implicaría la no incorporación de los sectores renuentes a la moratoria impositiva, al crédito bancario y a las rebajas arancelarias. La UIA no se mostró favorable. Según su criterio, el método de premios y castigos no era el más adecuado. Implícitamente, estaba anticipando su negativa a someterse al acuerdo de precios y procuraba que no se le aplicasen los "castigos” correspondientes.

En noviembre del mismo año, la UIA expresó nuevamente su oposición al acuerdo mediante un comunicado en que se oponía a las políticas de control de precios, dado que, a su juicio, producirían efectos contraproducentes en el desarrollo económico, disminuyendo la producción, incrementando costos y precios, bajando el consumo, la actividad fabril y el empleo. En el mismo comunicado se sostenía en tono extorsivo que tal ley de control de precios impedía el cumplimiento del régimen de pago de las deudas provisionales (La Nación, 1966).

En sintonía con la orientación industrialista bajo la tutela estatal que reclamaron en los primeros meses, la UIA sostuvo la necesidad de revertir ciertas tendencias de las condiciones de inserción en el mercado externo. En 1966, durante un almuerzo del Rotary Club de Buenos Aires ${ }^{5}$, Oneto Gaona disertó acerca de las posibilidades que abriría para la Argentina la conformación de la Asociación Latinoamericana de Libre Comercio (ALALC). Señalaron su resquemor a la existencia de una estructura local 
más afín a las importaciones que a las exportaciones que, de no revertirse, remarcaría las condiciones de debilidad de la industria argentina frente a sus competidores e impediría aprovechar las posibilidades que brindaba el ALALC. Demandaron, en función de ello, la intervención estatal con políticas orientadas a generar competitividad para el entramado industrial local. Entonces, el Estado debería subsidiar las tarifas de energía, resolver el problema de salarios altos no-competitivos (anulando el "costoso” sistema provisional) y devaluar la moneda para proteger a la industria nacional, contribuyendo de esa manera a que se alcancen de los estándares de competitividades, al menos latinoamericanos (La Nación, 1966).

A fines de 1966, la irresolución de las dificultades en materia económica le costó el cargo al ministro de Economía, que fue desplazado de su puesto por Onganía (Dromi 1988: 412). Los términos en los que fue instaurado el Acuerdo de Precios, la no aplicación de congelamiento salarial, y una devaluación muy tenue constituyeron los principales aspectos de desacuerdo de la UIA con la gestión de Salimei.

Salimei expresaba una estrategia diferente a la de la entidad industrial, y afín a la política reformista impulsada por las fracciones de la burguesía representadas por la Confederación General Económica. La resolución de la crisis económica, cuya principal expresión era la caída de la tasa de ganancia industrial, requería para la UIA medidas diferentes que anudaban una serie de alianzas distintas a las tejidas por Salimei. Como hemos visto en los documentos presentados al comienzo de la gestión económica, superar la crisis de acumulación demandaba para la UIA: la caída de los salarios reales y la reestructuración de los gastos estatales, el aumento de la productividad y la eficiencia, el disciplinamiento de los sectores obreros y la restructuración de la legislación laboral y previsional en virtud de disminuir el costo de la mano de obra. A su vez, se demandaba el apuntalamiento estatal para generar la competitividad industrial que permitiera apuntar hacia la conquista de los mercados internacionales. En el corto plazo, ello significaba proteger y subsidiar a la industria local, tomando como primera medida en ese sentido, una devolución de la moneda acorde a los niveles de protección y costos de la mano de obra requeridos para la restauración de la tasa de ganancia. La gestión Salimei estaba muy lejos de coincidir con los objetivos de la UIA.

El sector liberal de las Fuerzas Armadas, personal con el que se alineaba la UIA, habría operado para impedir la implementación completa de la política delineada por Salimei. El principal enfrentamiento fue con Álvaro Alzogaray, embajador argentino en Washington y hermano del General Julio Alzogaray, dirigente de la facción liberal. El motivo de discordia habría girado alrededor de la intención de Alsogaray de contraer un acuerdo con Estados Unidos para acercar inversores extranjeros, a la que se opuso Salimei (Rapoport 2000). A través de las críticas de Alzogaray, se expresaban los de toda la facción liberal, que no ahorraba cuestionamientos frente a la orientación económica dispuesta por Salimei. Finalmente, el 30 de diciembre de 1967, fue reemplazado por Adalbert Krieger Vasena, men- 
guando el enfrentamiento de los sectores más concentrados de la burguesía con el gobierno en materia de política económica.

\section{La alianza con Krieger Vasena}

Krieger Vasena provenía de las esferas empresariales, habiendo oficiado de asesor y miembro del directorio de varias grandes empresas. Obró como director de la National Lead, asociada en Argentina a Minera Aguilar, a la Compañía Minera Castaño Viejo y a Metalmina. También ocupó puestos dirigentes en la Compañía General de Refractarios de la Argentina. Asimismo se desempeñó como director de las firmas Alejandro Llauró e Hijos e Investaires, pertenecientes a su suegro, Alejandro Llauró, dirigente de la UIA durante el período (Muchnik 2010).

Las intenciones de Vasena eran solucionar los problemas de ineficiencia de los sectores público y privado, raíz del estancamiento económico. Su plan consistía en redistribuir los recursos canalizándolos hacia los sectores más eficientes de cada actividad, premiando a los más productivos.

El plan implementado radicó en una devaluación del 40\% del peso. A partir de ese momento (principios de 1967) regiría un tipo de cambio fijo. Para compensar los efectos de transferencias de ingresos entre ramas, se impusieron retenciones a las exportaciones que oscilaban entre el 16 y el $25 \%$, especialmente aplicadas a las exportaciones agropecuarias.

Dado que la devaluación actuaba como una barrera de contención de productos importados se redujeron los aranceles aduaneros en un 50\%, con el objetivo habilitar la importación de maquinarias para modernizar los sistema de producción y comprar los insumos necesarios sin aumentar los costos finales de producción. De esta manera se incentivaba el aumento de la productividad permitiendo la importación de maquinarias.

Los tres elementos mencionados (devaluación, retenciones y aranceles) actuaban como un doble tipo de cambio (Rapoport 2000: 530; Braun 1973: 29). Uno bajo para las exportaciones agropecuarias combinado con uno más alto para las exportaciones industriales, la importación de productos de consumo industrial y las transacciones financieras. Por otra parte, se implementaron incentivos fiscales a las inversiones industriales. Especialmente, a partir de exenciones impositivas del orden del 50\% en la compra de maquinarias, incrementando su importación.

En el ámbito rural se dio por concluido el sistema de prórroga automática y congelamiento de arrendamientos, reclamado por el sector terrateniente durante décadas. Con respecto a las relaciones económicas internacionales, el 13 de marzo de 1967 se firmó el acuerdo Stand By con el FMI por 125 millones de dólares, cuyo objetivo era contener la inflación para facilitar la atracción de capitales extranjeros.

El ministerio a su vez congeló los salarios mediante un decreto de 
fines de marzo de 1967, restringiendo los aumentos hasta fines de 1968. También aumentó las tarifas de los servicios públicos, los impuestos a las ventas y propiedades y redujo el empleo público. La respuesta gubernamental a la lucha iniciada por un sector de la CGT frente a la desvalorización del precio de la fuerza de trabajo, fue la suspensión de la personería gremial a Unión Obrera Metalúrgica, Federación Obrera Tucumana de la Industria del Azúcar (FOTIA) y la Federación de Obreros y Empleados Telefónicos de la República Argentina (FOETRA). A pesar de este golpe, la cúpula de la Confederación General del Trabajo liderada por Augusto Vandor, dio marcha atrás con el plan de lucha propuesto ante el plan de ajuste, buscando evitar las medidas represivas y enemistarse abiertamente con el régimen (De Riz 2000: 58). Dentro del recorte de conquistas gremiales se modificaron los regímenes de trabajo en los puertos y ferrocarriles y se profundizó la reestructuración de los ingenios azucareros. Se sancionó la Ley de Arbitraje Obligatorio que posibilitaba la intervención del Estado en los conflictos obrero-patronales y propiciaba los despidos sin indemnización (Rapoport 2005: 517).

La asunción de Krieger Vasena marca entonces el inicio de una intervención diferente por parte de la Unión Industrial. En efecto, poco después de los anuncios del nuevo plan económico, en el verano de 1967, la entidad declaró su adhesión enfatizando la necesidad de adoptar medidas contra la inflación y las subas de salario para reducir los costos de producción. Anticipaba, a su vez, su intención de apoyar un acuerdo de precios para contener la inflación, en un contexto en el cual la devaluación ya había operado disminuyendo los salarios reales (La Nación, 1967).

A diferencia de la Confederación General Económica, que condenó las medidas adoptadas ${ }^{6}$, la UIA puso de relieve su acuerdo con la devaluación del peso en un 40\%, y la nueva política arancelaria, mediante la que se redujeron los impuestos a la importación favoreciendo el ingreso de maquinarias para la modernización de los procesos productivos. ${ }^{7} \mathrm{La}$ sobrevaluación del peso reinante hasta la fecha implicaba una disminución de la tasa efectiva de protección de la industria radicada en Argentina. La mayor capacidad de importación que genera un tipo de cambio sobrevaluado implicaba la agudización de la competencia con los capitales extranjeros. Por esta razón, la UIA requería que se devalúe la moneda para que actúe como protección de hecho. Asimismo, la caída de la tasa de ganancia impulsaba la urgencia de aumentar la productividad del trabajo y disminuir los costos para acaparar una porción de la ganancia en disminución. La disminución de los costos internos de mano de obra y la caída de los salarios reales implicados en la devaluación operaban en el sentido de las necesidades de las fracciones de la burguesía industrial representadas por la UIA. A su vez, la eliminación de trabas arancelarias para la importación de maquinaria venía a cubrir la necesidad de incorporar capital fijo para mejorar la productividad del trabajo.

El Acuerdo de Precios, motivo de una férrea oposición de la UIA a Salimei, fue finalmente firmado en marzo de 1967. La asunción Krieger 
Vasena, y centralmente, la devaluación que abarataba el costo de la mano de obra, marcaron la convergencia entre la UIA y el titular de economía en torno a esta medida. Este compromiso fue expresado en varias oportunidades, una de ellas, con motivo de la adhesión de la entidad a la reedición del Acuerdo en enero de 1969. Oneto Gaona, en ese entonces ex presidente de la entidad, exaltó la supuesta espontaneidad del apego al Acuerdo en 1967. En realidad, la firma del mismo sólo una vez asumido Krieger Vasena hace pensar en una acción concertada de boicot de ciertos sectores de la burguesía a Salimei y un acuerdo estratégico con el nuevo ministro. ${ }^{8}$

La adhesión de la UIA a la política delineada por Krieger Vasena no fue circunstancial, y se mantuvo a lo largo del tiempo. Aún en 1969, en un almuerzo ofrecido por la Cámara de Comercio Británica, el presidente de la UIA, Elbio Coelho, señaló su acuerdo con respecto a la política económica en curso: "Los empresarios vemos la gradual pero sana transformación que se está produciendo en nuestro país desde hace un par de años.” (Cronista Comercial, 1969). Destacó también que Argentina contaba con buenas condiciones para la recepción de inversiones extranjeras debido a la "alta calidad de los recursos humanos", es decir, mano de obra calificada y barata; un régimen económico abierto y sin restricciones para la remisión de utilidades y un mercado interno en expansión.

En líneas generales entonces, se observa una bienvenida calurosa a Krieger Vasena por parte de la UIA y el acuerdo con la estrategia a desarrollar, claramente opuesta a la actitud adoptada frente a Salimei. No obstante, más allá del acuerdo con la línea general, la UIA intervino durante la gestión criticando, manifestando su apoyo o reclamando medidas frente a aspectos puntuales de las políticas implementadas. Veamos entonces las exigencias de la UIA a Krieger Vasena.

\section{Exigencias de la UIA}

Ni bien asumido el nuevo ministro, la UIA, como parte de ACIEL ${ }^{9}$, expuso un programa que se componía de una serie de medidas tendientes a la liberalización de la economía y reducción de los costos de fuerza de trabajo mediante la eliminación de conquistas obreras. En relación a este último punto, también inquietaba el poder alcanzado por ciertos sectores sindicales, asentado económicamente en los aportes compulsivos y la potestad para negociar las condiciones laborales. Se destaca también la intención de gozar de beneficios impositivos para la modernización de las plantas, es decir que el Estado subvencione la puesta a punto de los capitales para incrementar su competitividad.

En sintonía con la búsqueda de reducción salarial y aumento de la tasa de explotación declamada al menos desde 1966, en septiembre de 1967 la UIA expresó su conformidad con las medidas de congelamiento salarial dispuestas por el gobierno, señalando que contribuirían a la estabilización de los costos industriales. 
Un recurrente motivo de reclamo fueron las diferencias de salarios que debían pagar los empresarios radicados en diferentes provincias de la Argentina de acuerdo con la vigencia del sábado inglés y las quitas zonales. Como solución, la UIA proponía la implementación de medidas compensatorias.

Pocos meses antes de la rebelión popular de 1969 denominada “Cordobazo", Juan Oneto Gaona, ex presidente de la UIA, objetó las disposiciones de una nueva ley laboral (18.016) de 1969 mediante una nota al ministro Krieger Vasena. Impugnó una cláusula que habilitaba que en las convenciones colectivas de trabajo se dispusieran contribuciones obligatorias hacia las obras sociales sindicales. Se argumentaba que se "coercionaba" a los trabajadores a aportar compulsivamente a una cobertura médica no elegida, e indirectamente, a afiliarse al sindicato.

La racionalización del aparato estatal constituyó otro aspecto del programa sobre el que la UIA recargó las tintas. Además de la mención en las declaraciones al inicio de la dictadura de 1966, la entidad insistió en numerosas oportunidades sobre este punto, recalcando la insuficiencia en las medidas implementadas por el gobierno en la materia. Ante la elaboración del presupuesto 1968, la UIA emitió un documento con un balance del año y consideraciones sobre el próximo en el que declaró que el Estado es el único sector que no ha procedido a sanear su estructura. El logro de este objetivo permitiría prescindir de la emisión monetaria para cubrir los gatos estatales ni recurrir a impuestos extraordinarios. Las miradas de la entidad se dirigían principalmente a la reducción de los gastos corrientes, es decir de aquella porción del gasto público destinada puramente al consumo sin la generación de una mercancía como contrapartida. El pago de sueldos y la compra de bienes y servicios para garantizar el funcionamiento del aparato administrativo se encuentran dentro de este concepto.

Un almuerzo de IDEA ${ }^{10}$, así como una reunión en Río Cuarto (Córdoba) ante el Centro Comercial e Industrial, fueron ocasiones en las que el nuevo titular de la UIA electo en 1968, Elbio Coelho ${ }^{11}$, insistió sobre la urgencia de racionalizar el aparato estatal. A través de un comunicado de ACIEL, en mayo de 1969, la entidad volvió a insistir en la eliminación del déficit presupuestario.

No obstante, estas exigencias de reducción de los gastos estatales no implicaban la adscripción a un discurso extremadamente "liberal", entendido como la concreción de un "Estado mínimo". Esas apelaciones de la UIA al saneamiento de las cuentas estatales se combinaron con las demandas de protección hacia ciertos sectores empresarios y el pedido de intervención estatal con políticas de promoción industrial. En efecto, en 1968 la UIA auspició la realización del Congreso Regional de Industriales del Centro-Noroeste Argentino, en el que se trataron las solicitudes al gobierno de regímenes de promoción industrial que comprendieran el total de territorio nacional. Asimismo, la eliminación de la superposición impositiva, y la vigencia del "sábado inglés", que implicaba incrementos salariales hasta 
en un 9.1\% en algunas provincias argentinas, también fueron objeto de reclamos en aquella ocasión.

En vísperas del Cordobazo, la UIA volvió sobre este último problema en conjunto con la Federación Argentina de Industria Metalúrgica y ACIEL, enviando notas al ministro de Economía y a los gobernadores de Córdoba, Mendoza, Santiago de Estero, San Juan y Tucumán. Advertía sobre el riesgo de paralización de las actividades industriales si se avanzaba en la eliminación de las quitas zonales ${ }^{12}$ del 9.1\% respecto de los regímenes salariales de Capital Federal, Buenos Aires, Rosario y Santa Fe. La eliminación de las quitas era una medida reclamada por la clase obrera, que venía protagonizando un proceso de reclamos que derivó, pocas semanas después, en la insurrección cordobeza. La UIA resaltaba que las diferencias salariales que establecían las quitas eran compensadas por la mayor cantidad de jornales que el empleador debía pagar debido a la vigencia del "sábado inglés” en estas provincias. A su vez, proponía el establecimiento de compensaciones que suplieran lo que se perdería de derogarse las quitas zonales. Se demandaban tales compensaciones argumentando la necesidad de un incentivo a la instalación de plantas metalúrgicas en el interior del país, ya que dadas las circunstancias mencionadas, no encontrarían ventajas para tal localización.

De esta manera vemos una contradicción aparente entre las demandas de reducción de los gastos estatales y el reclamo de medidas promocionales que, obviamente, implicaban aumentar el gasto estatal. Sin embargo, no existe tal contradicción entre una y otra: la UIA exigía un redireccionamiento de los gastos estatales hacia el sostenimiento de la industria. Lo que solicitaba, en definitiva, era que la plusvalía e impuestos al consumo no se utilizaran en trabajo improductivo y se destinaran a sostener la acumulación. Posición que poco tiene de “liberal", en el sentido vulgar del término, pero se inscribe dentro del campo del programa burgués.

Con respecto a la política arancelaria, la UIA manifestaba, por un lado, su apoyo a la rebaja de los gravámenes para las materias primas y bienes de capital que no se producían en el país, dado que distorsionaban la estructura de costos de los bienes industriales. Coincidían, a su vez, con el sentido general de las medidas adoptadas, que apuntaban a mejorar la eficiencia del capital local exponiéndolo a la competencia con manufacturas importadas. Sin embargo, se reclamaba un ajuste en la política de tarifas, ya que ese tipo de medidas dejaban de lado otros factores que afectaban la competitividad de la industria local, e incluso podrían llegar a ser negativas, exponiendo a la competencia externa a ramas y sectores que no habían alcanzado los niveles de eficiencia necesarios para enfrentarla.

Si bien defendían la apertura del comercio exterior, ya que esta potenciaría la competitividad de la industria local al exponerla a la competencia con los capitales extranjeros, señalaban que los aranceles no eran la 
única ni la principal razón que distorsiona la estructura de costos industriales, y que dificultaban su colación en el mercado mundial. Se volvía a aludir, nuevamente, a la cuestión de la "eficiencia", y con ello a la productividad y a los costos salariales, con lo cual, se supeditaba la apertura a la competencia internacional a un ajuste interno de los costos laborales y al aumento de la productividad.

No obstante las prédicas a favor de la exposición de los capitales locales a la competencia extranjera para obligarlos a aumentar su eficiencia, en los hechos se demandaba permanentemente una protección selectiva y se condicionaba la apertura a la resolución del problema de la productividad, es decir, a los avances sobre las condiciones obreras. En primer lugar, la devaluación, aplaudida por la entidad, implicó una protección de hecho. En segundo lugar, la propuesta en materia de comercio exterior de la UIA tenía un doble carácter: se pretendía cubrir las necesidades de importación de maquinaria e insumos (y por lo tanto, se demandaba liberalización en estos rubros) y, a su vez, el resguardo de ciertos capitales aplicando medidas proteccionistas. En definitiva, se reclaman medidas "liberales” exclusivamente para eliminar los sobreprecios pagados a ciertos capitales nacionales, producto de la protección arancelaria, y una protección selectiva para ciertas ramas.

En 1969, a la vez que se distinguía el impulso exportador del régimen arancelario se insistía cada vez más en la necesidad de resolver las debilidades internas. En efecto, Julio Ferloni, presidente del Departamento de Comercio Exterior de la UIA, expresó que la liberalización de la economía requería un período previo de protección de la industria nacional debido a la deficiencia relativa de la misma en relación a sus competidores internacionales. La entidad sostuvo que la política arancelaria debía promover y proteger las actividades industriales del país. A su entender, en aquel período la política arancelaria no estaba orientada a permitir el desarrollo industrial sino a obtener ciertos objetivos específicos.

En definitiva, observamos una tensión entre el aplauso a la liberalización de la economía encabezada por Krieger Vasena y la necesidad de cierta protección a la industria local, ineficiente para competir en el mercado mundial. La tutela estatal era presentada como el paso previo para la posterior apertura de la economía y su regimentación a partir de criterios puramente de mercado. Sumado a esto, las iniciativas de promoción industrial y rebajas salariales (directas e indirectas) dan cuenta de las debilidades para posicionarse competitivamente frente a los grandes capitales internacionales. Por otra parte, el pedido de discrecionalidad en el otorgamiento de recursos estatales y de rebajas arancelarias de ciertas mercancías evidencia la competencia inter-capitalista en el ámbito nacional. La cuestión radicaba, básicamente, en quién pagaba la crisis económica: qué ramas o empresas se beneficiarían de la protección y de la promoción, y cuáles pagarían los costos de afrontar una mayor competencia externa a fin de obtener insumos y maquinarias más baratos. 


\section{Conclusiones}

La acción de la UIA durante la mayor parte del gobierno de Onganía tendió a imponer su programa de salida a la crisis. La caída de la tasa de ganancia y de la productividad industrial requería de medidas que permitieran poner a punto nuevamente a las empresas individuales para relanzar la acumulación de capital. La baja de la renta diferencial, desde 1963, disminuía la capacidad de transferencia del sector agropecuario a la industria y por lo tanto, la masa de ingresos que había permitido sostener una experiencia como la del peronismo ya no se encontraba disponible. En este contexto se agudizan los enfrentamientos interburgueses y capital-trabajo, a fin de imponer una salida a la crisis y determinar qué fracciones cargaran con sus costos.

La UIA formuló, en este contexto, un conjunto de medidas tendientes a reproducir su capital real en las condiciones que el mercado dictaba para mantenerse en pie. En este sentido, las políticas propuestas por la entidad se dirigían a disminuir el peso de los salarios en los costos de producción, reduciendo salarios reales, atando los sueldos a la productividad, eliminando conquistas sociales y reduciendo el poder de negociación de los sindicatos. Abrogaban también por una protección de la industria local: saludaron la devaluación de la moneda, que imponía de hecho la protección del mercado interno provocando una transferencia de valor a favor de la industria mercado internista. A pesar de recomendar una eliminación de tarifas y la liberalización de los mercados, se opusieron a una apertura total, demandando la disminución de tarifas sólo en lo referente a ciertos insumos y maquinarias industriales, que permitirían aumentar la productividad del trabajo y disminuir sus costos de producción. A contramano de su pretendido "liberalismo", reclamaron que se mantenga la protección industrial cuando ésta afectaba a las empresas y ramas que representaba, posponiendo todo intento de apertura aduanera a la eliminación de las "distorsiones salariales”. La inexistencia, sin embargo, de una demanda de protección general para el conjunto de la industria nacional da cuenta de que en la estrategia de la UIA existían capitales a los que se debía quitar la tutela estatal y dejar sucumbir ante la competencia internacional.

En lo referente al rol del Estado, en consonancia con el discurso "liberal clásico", demandaron disminuir todo gasto de plusvalía en actividades no redituables (por ejemplo en empleo estatal). Reclamaron permanentemente por el recorte de los gastos estatales, por el saneamiento de las cuentas públicas y la eliminación del déficit. Sin embargo, también demandaron la intervención del Estado, que debía solventar el aumento de la competitividad de la industria local subsidiando tarifas de servicios y ampliando los regímenes de promoción industrial.

Su estrategia de resolución de la crisis aparece como favorable a eliminar los capitales menos eficientes para el espacio nacional, aunque dada la ineficiencia de la mayoría de ellos en el mercado internacional, debía reclamar cierta tutela estatal. Claramente, la renta ya no alcanzaba 
para sostener a todos por igual, y la UIA operó para que no fueran las fracciones que ella representaba quienes pagasen los costos de la crisis, sino los industriales más pequeños y la clase obrera. En esta lógica se inscribe su política, que lejos está de ser anti-industrial o anti-estatal, como pretenden aquellos que califican a la UIA de "liberal”. Es la estrategia que deben adoptar los capitales no competitivos para desarrollar sus industrias en un contexto en el que la disminución del principal elemento de compensación de las debilidades del capitalismo local, la renta, obligaba a imponer un ajuste. Por un lado, promovían una concentración y centralización "regulada” y, por el otro, y he aquí lo más importante, impulsaban la ruptura de las relaciones que daban sustento al reformismo peronista. Con un mercado interno muy limitado, sólo mediante la drástica disminución del precio de la fuerza de trabajo la Argentina industrial podía tener alguna oportunidad en el mercado mundial. Esta ofensiva, como veremos, chocó en 1969 con un límite impuesto por el proletariado.

Los efectos de la aplicación del programa de la UIA implicaron un proceso de concentración y centralización del capital. Como advertimos, la cuestión era qué capitales pagaban la crisis. En un contexto de caída de renta, el Estado no puede subsidiar a todos, apareciendo disputas por la compensación necesaria para su reproducción. Asimismo, la entrada de capitales extranjeros agravó la crisis en muchas ramas de la industria. Los resultados del proceso: quiebra de pequeños capitales y aumento de la desocupación producto del cierre de empresas y el reemplazo de fuerza de trabajo por maquinarias. 


\section{Notas}

${ }^{*}$ El artículo es parte de la tesis doctoral de la autora, en evaluación.

${ }^{1}$ Ver críticas a ésta concepción del comportamiento de la burguesía nacional en Sartelli, E.: "El enigma de Proteo. A propósito de J. Sábato, Larry Sawers y el estancamiento de la economía argentina”, Ciclos nº 10, IHES, FCE, Buenos Aires, 1996; Kornblihtt, J.: Crítica del marxismo liberal, Ediciones ryr, Buenos Aires, 2008, pp. 13 a 58; Baudino, V.: El ingrediente secreto, Ediciones ryr, Buenos Aires, 2008, pp. 17 a 48.

${ }^{2} \mathrm{El}$ bonapartismo es un régimen político asentado en una paridad de fuerzas entre las clases y fracciones de la clase dominante. se trata de un personal que se eleva por encima de ese equilibrio e intenta conciliar, en mayor o menor medida (y momentáneamente), los diferentes intereses con el objetivo de "congelar" el desarrollo de las contradicciones. pero ese régimen, bajo el capitalismo, siempre responde en última instancia a la clase dominante. véase Trotsky, L.: La lucha contra el fascismo en Alemania, Ediciones Pluma, Buenos Aires, 1974, t. II, p. 76.

${ }^{3}$ La Asociación Católica de Dirigentes de Empresa era (y es) una corporación integrada por directivos de empresas, fundada en 1952 por la Acción Católica. Contaban con estrechos lazos con las Fuerzas Armadas, y sus miembros ocuparon cargos públicos bajo el gobierno de Onganía (la mayoría del gabinete de Salimei pertenecía a dicha institución). Miembros de la UIA, como Van Perborg formaban también en sus filas. Ver Verbitsky, H. (2008): La iglesia en la Argentina: De Lonardi al Cordobazo (1955-1969), Sudamericana, Buenos Aires.

${ }^{4}$ Ex ministro de Economía del gobierno de Arturo Frondizi.

${ }^{5}$ El Rotary Club, entidad que nuclea empresarios nacida en Estados Unidos, ha sido un lugar privilegiado de exposición de las posiciones de la UIA. Otra entidad católica vinculada a la corporación, ha sido en el período la organización del monje francés Georges Grasset. Roberto Petracca, dirigente de la UIA, era parte de la mencionada institución. Verbitksy, H.: op. cit., p. 229.

${ }^{6}$ Memoria y Balance, CGE, 1967. En un principio la CGE saludó los objetivos de "modernización” de la economía, aunque pasó rápidamente a la oposición a la gestión de Krieger Vasena.

${ }^{7}$ La Cámara Argentina de Comercio también apoyó la disminución de los aranceles a las importaciones. Niosi, J.: op. cit., p. 163.

${ }^{8}$ Entrevista a Juan Martín Oneto Gaona publicada en La Nación, 24 de enero de 1969. Ver también Clarín, 24 de enero de 1969.

${ }^{9}$ La UIA era parte de la dirigencia de ACIEL (Acción Coordinadora de Instituciones Empresarias Libres), entidad que agrupaba a las corporaciones representantes de las capas más concentradas de la burguesía que operaba en Argentina en el período estudiado.

${ }^{10}$ Institución empresarial fundada en 1960 especializada en elaboración de planes de negocios y formación de cuadros gerenciales. 
${ }^{11}$ En 1967 asume, elecciones mediante, el nuevo presidente de la UIA, Elbio Coelho. A juicio de Schvarzer, éste representaba los intereses de los pequeños y medianos capitales a diferencia de Oneto Gaona, quien pretendía que la UIA sea sólo de los grandes. Schvarzer, J., 1996.

${ }^{12}$ Las quitas zonales eran un beneficio promocional que permitía a los capitalistas de determinadas provincias descontar un porcentaje del salario sobre el acordado en convenciones colectivas nacionales. Estas quitas estaban destinadas a equilibrar los jornales de las provincias en las que regía el "sábado inglés" con las que no. La exigencia obrera de derogar las quitas zonales fue uno de los principales reclamos del Cordobazo. Balvé, B. y Balvé, B.(2005): El 69, Ediciones ryr, Buenos Aires: p. 36. 


\section{Fuentes}

-Publicaciones periódicas

Clarín, varios años.

Cronista Comercial, varios años.

La Nación, varios años.

La Prensa, varios años.

Primera Plana, varios años.

Revista Mercado, varios años.

-Publicaciones específicas de la industria

Memoria y Balance de la Unión Industrial Argentina, varios años.

Revista de la Unión Industrial Argentina, varios años.

Guía de Accionistas, 1959-1960.

Guía de la Industria, 1974.

Quién es quién, 1958-1959.

\section{Bibliografía}

Anzorena, O. (1998), Tiempo de violencia y utopía: del Golpe de Onganía al Golpe de Videla, Ediciones Colihue, Buenos Aires, p. 33.

Balvé, B. y Balvé, B. (2005), El 69, Ediciones ryr, Buenos Aires.

Basualdo, E. M. (2006), Estudios de Historia Económica Argentina. Desde mediados del Siglo XX a la actualidad, Siglo XIX. Buenos Aires.

Ídem (2009), “La evolución del sistema previsional argentino”, Documento de trabajo $n^{\circ} 2$, CIFRA, Buenos Aires.

Baudino, V. (2008), El ingrediente secreto, Ediciones ryr, Buenos Aires.

Bil, D. (2007), Descalificados. Proceso de trabajo y clase obrera en la industria gráfica (1890-1940), Ediciones ryr, Buenos Aires.

Bra, G. (1985), El gobierno de Onganía, Ceal, Buenos Aires, 1985, pp. 9 a 24.

Caggiano, R. (1975), Notas sobre el desarrollo de la burguesía nacional. La Confederación de la Industria y La UIA en el período 1957-1973, Centro de Estudios Urbanos y Regionales, Instituto Torcuato Di Tella, Buenos Aires.

Casanova, P. (1998), El Estado en América Latina: teoría y política, Siglo XXI, Buenos Aires, p. 203. 
Cúneo, D. (1967), Comportamiento y crisis de la clase empresaria. Pleamar, Buenos Aires.

De Dromi, M.L (1988), Historia política Argentina, Editorial Astrea y Depalma, p. 412.

De Ímaz, J. L. (1965), Los que mandan, Eudeba, Buenos Aires.

Engels, F. (1983), El origen de la familia, la propiedad privada y el Estado, Madrid, pp. 290-296.

Kornblihtt, J. (2008), Crítica del marxismo liberal, Ediciones ryr, Buenos Aires, pp. 13 a 58.

Kosacoff, B. y Aspiazu, D. (1989), La industria argentina: desarrollo y cambios estructurales, CEPAL, Buenos Aires.

Lázzaro, S. (comp.) (2000), Estado y cuestión agraria en Argentina y Brasil, UNLP, La Plata.

Marx, Karl. (2002), El Capital, Siglo XIX, Buenos Aires.

Ídem (1998), El dieciocho brumario de Luis Bonaparte, Need, Buenos Aires, pp. 60-61.

Muchnik, D. (2010), “De Krieger Vasena a Cavallo”, Perfil, 18 de abril de 2010.

Niosi, J. (1974), Los empresarios y el Estado Argentino (1955-1969), Siglo XXI Editores, Buenos Aires.

O’Donnell, G. (1982), El Estado burocrático-autoritario. Triunfos, derrotas y crisis, Editorial Belgrano, Buenos Aires.

Ídem (2008), Catacumbas, Prometeo, Buenos Aires.

Peralta Ramos, M. (2007), La economía y política argentina: poder y clases sociales (1930-2006), FCE, Buenos Aires.

Perina, R. (1983), Onganía, Levingston, Lanusse: los militares en la política argentina, Editorial de Belgrano, Buenos Aires, p. 28.

Rapoport, M. y otros (2000), Historia económica, política y social de la Argentina (1880-2000), Macchi, Buenos Aires.

Sartelli, E. (2007), La plaza es nuestra. El argentinazo a la luz de la lucha de la clase obrera en la Argentina del siglo XX, Ediciones ryr, Buenos Aires. 
Ídem (1996), “Celeste, blanco y rojo. Democracia, nacionalismo y clase obrera en la crisis hegemónica (1912-1922)”, Razón y Revolución, nº 2, Buenos Aires, primavera de 1996.

Ídem (1996), “El enigma de Proteo. A propósito de J. Sábato, Larry Sawers y el estancamiento de la economía argentina”, Ciclos $n^{\circ} 10$, IHES, FCE, Buenos Aires.

Schvarzer, J. (1991), Empresarios del pasado. La Unión Industrial Argentina, Imago Mundi, Buenos Aires.

Trotsky, L. (1974), La lucha contra el fascismo en alemania, Ediciones Pluma, Buenos Aires, t. II, p. 76.

Verbitsky, H. (2008), La iglesia en la Argentina: De Lonardi al Cordobazo (1955-1969), Sudamericana, Buenos Aires.

Recibido: 14.09.2011

Aceptado: 25.07.2012 